\title{
Interannual variabilities, long-term trends, and regulating factors of low-oxygen conditions in the eastern Pearl River Estuary
}

\author{
Zheng Chen ${ }^{1}$, Bin Wang ${ }^{4}$, Chuang $\mathrm{Xu}^{5}$, Zhongren Zhang ${ }^{1,6}$, Shiyu $\mathrm{Li}^{1}$, Jiatang $\mathrm{Hu}^{1,2,3,{ }^{*}}$ \\ ${ }^{1}$ School of Environmental Science and Engineering, Sun Yat-sen University, Guangzhou, 510275, China
}

$5{ }^{2}$ Guangdong Provincial Key Laboratory of Environmental Pollution Control and Remediation Technology, Guangzhou, 510275, China

${ }^{3}$ Southern Marine Science and Engineering Guangdong Laboratory (Zhuhai), Zhuhai, 519000, China

${ }^{4}$ Department of Oceanography, Dalhousie University, Halifax, Nova Scotia, B3H 4R2, Canada

${ }^{5}$ Center for Water Resources and Environment, Sun Yat-sen University, Guangzhou, 510275, China

$10{ }^{6}$ Guangdong Zhihuan Innovative Environmental Technology Co., Ltd, Guangzhou, 510030, China

Correspondence to: Jiatang Hu (hujtang@mail.sysu.edu.cn)

\begin{abstract}
The summertime low-oxygen conditions in the Pearl River Estuary (PRE) have experienced a significant expansion in spatial extent associated with notable deoxygenation in recent decades. Nevertheless, there is still a lack of quantitative understanding of the long-term trends and interannual variabilities in oxygen conditions in the PRE as well as

15 the driving factors, which was comprehensively investigated in this study using monthly observations in the eastern PRE during 1994-2018. To evaluate the changes in scope and intensity of oxygen conditions, an indicator (defined as the Lowoxygen Index, LOI) that integrates several metrics related to low-oxygen conditions was introduced through the principal component analysis (PCA). Moreover, primary physical and biogeochemical factors controlling the interannual variabilities and long-term trends in oxygen conditions were discerned, and their relative contributions were quantified by the multiple regression analysis. Results showed that the regression models explained over $60 \%$ of the interannual variations in LOI. Both the wind speeds and concentrations of dissolved inorganic nitrogen (DIN) played a significant role in determining the interannual variations (by $39 \%$ and $49 \%$, respectively) and long-term trends (by $39 \%$ and $56 \%$, respectively) in LOI. Due to the increasing nutrient loads and alterations in physical conditions (e.g. the long-term decreasing trend in wind speeds), coastal eutrophication was exaggerated and massive marine-sourced organic matter was subsequently produced, thereby resulting in an expansion of intensified low-oxygen conditions. It has also driven a shift in the dominant source of organic matter from terrestrial inputs to in situ primary production, which has probably led to an earlier onset of hypoxia in summer. In summary, the eastern PRE has undergone considerable deterioration of low-oxygen conditions in the context of substantial changes in anthropogenic eutrophication and external physical factors.
\end{abstract}

Keywords: Dissolved oxygen; Low-oxygen conditions; Interannual variations; Long-term deoxygenation; Pearl River 
https://doi.org/10.5194/bg-2021-358

Preprint. Discussion started: 19 January 2022

(c) Author(s) 2022. CC BY 4.0 License.

\section{(c) (i)}

\section{Introduction}

Dissolved oxygen (DO) plays a vital role in maintaining the good functioning of aquatic ecosystems. Hypoxia (DO $<2$ $\mathrm{mg} / \mathrm{L}$ ) could lead to a marked reduction in habitat for aquatic creature (Ludsin et al., 2009) and imposes detrimental effects on ecosystem community structure and energy flow (Diaz and Rosenberg, 2008). In recent decades, long-term exacerbation on hypoxia in terms of its spatial extent and intensity has been documented in estuaries and coastal waters worldwide, including the Baltic Sea (Conley et al., 2011; Meier et al., 2019), the northern Gulf of Mexico (Obenour et al., 2013; Laurent and Fennel, 2019), Chesapeake Bay (Li et al., 2016; Ni et al., 2020), the Yangtze River Estuary (Zhu et al., 2011; Zhang et al., 2021), and the Pearl River Estuary (Li et al., 2020; Hu et al., 2021). In addition, changes in the phenology of hypoxia were also reported. For example, in Chesapeake Bay, hypoxic volume has shown a significant increase in early summer but a slight decrease in late summer since 1985 (Murphy et al., 2011; Testa et al., 2018). Zhou (2014) also found that the timing of maximum hypoxic volume in Chesapeake Bay was advanced from late July to early July during 1985-2010.

A great number of studies have indicated that the exacerbation of hypoxia in coastal systems was closely related to human activities, such as urbanization and industrialization (Breitburg et al., 2018). Due to the anthropogenic influence, massive terrestrial organic matter and nutrients were discharged into estuaries and coastal waters, leading to intense microbial respiration (Rabalais et al., 2010). Also, excessive nutrient inputs could further stimulate the growth of phytoplankton and exacerbate eutrophication, with a dramatic increase in oxygen demand from marine-sourced organic matter (Fennel and Testa, 2018). Meanwhile, physical processes such as stratification (Rabalais et al., 1991), convergence and migration of water masses ( $\mathrm{Li}$ et al., 2021), and upwelling (Feng et al., 2014) could regulate the spatial extent and intensity of hypoxia as well. These processes are closely linked to wind forcing and freshwater discharge (Feng et al., 2012a;

$50 \mathrm{Yu}$ et al., 2015). In general, the physical and biogeochemical processes exert joint impacts on the generation and development of hypoxia, but different mechanisms may predominate in different systems due to their distinctive natural conditions (e.g. topography) and pressure from anthropogenic pollution. $\mathrm{Ni}$ (Ni et al., 2020) quantified the contributions of ocean warming, sea level rise, and nutrient load reduction to the long-term changes in hypoxia in Chesapeake Bay through numerical simulation experiments, suggesting that ocean warming was the dominant factor. Forrest (Forrest et al., 2011) investigated the effects of various processes on the interannual variations of hypoxia in the northern Gulf of Mexico by statistical methods and pointed out that the east-west winds and nutrient loads each accounted for a considerable contribution. While in the Yangtze River Estuary, studies showed that vertical density stratification, which was heavily influenced by a combination of freshwater inputs, various water masses, and winds, was the key factor controlling the interannual changes in hypoxia (Chi et al., 2020).

With the rapid socioeconomic development, the Pearl River Estuary (PRE) has received a large amount of pollutants and nutrients, resulting in a series of environmental problems, including eutrophication, red tide, and hypoxia (Dai et al., 2008; Li et al., 2020). Low-oxygen (DO $<4 \mathrm{mg} / \mathrm{L}$ ) and hypoxic conditions were first observed in the eastern PRE in the 1980s (Yin et al., 2004) and have been frequently reported in the Lingdingyang Bay, Modaomen Bay, and Huangmaohai 
https://doi.org/10.5194/bg-2021-358

Preprint. Discussion started: 19 January 2022

(c) Author(s) 2022. CC BY 4.0 License.

\section{(c) (i)}

Bay (Li et al., 2020; Su et al., 2017; Cui et al., 2018; Shi et al., 2019) since 2000. Previous studies have shown that hypoxia in the PRE typically occurred in the bottom waters during summer (Yin et al., 2004), driven by strong stratification and sediment oxygen consumption (Zhang and Li, 2010; Wang et al., 2016). Due to relatively shallow topography, short water residence time (Rabouille et al., 2008) and short maintenance of stratification (Luo et al., 2009; Lu et al., 2018) hypoxia in the PRE appeared to be episodic and localized (Rabouille et al., 2008). However, this long-standing point of view has been challenged by recent observations showing the emergence of large low-oxygen and hypoxic extents. The area affected by low oxygen in the bottom waters of the PRE was estimated to be around 1,000 $\mathrm{km}^{2}$ in 2010 (Wen et al., 2020) and 1,500 $\mathrm{km}^{2}$ in 2015 (Li et al., 2018). With the increasing availability of observations, an apparent expansion of hypoxia with large interannual variations has been revealed from the data during 1976-2017 (Hu et al., 2021). Nevertheless, due to the scarcity of observations in both time and space, a clear understanding of the long-term trend and interannual changes in hypoxia in the PRE as well as the associated drivers is still lacking, especially from a quantitative perspective.

In this study, we perform a quantitative analysis on the long-term oxygen changes (trend and interannual variability) by utilizing observational data collected by the Environmental Protection Department of Hong Kong (HKEPD) in the eastern waters of the PRE. The HKEPD monitoring program provides over 30 years of oxygen and related data at certain coastal sites (see details in section 2.1 below), allowing us to better quantify the long-term deoxygenation in the region. Moreover, we also aim to discern the key factors controlling the interannual variability and long-term trends in the low-oxygen conditions and to quantify the relative contribution of each primary factor using multiple regression models (Murphy et al., 2011; Forrest et al., 2011; Wang et al., 2021).

\section{Materials and methods}

\subsection{Data sources}

Monthly monitoring data at 10 stations (Figure 1) in the eastern PRE $\left(113.8 \sim 114.5^{\circ} \mathrm{E}, 22.1 \sim 22.6^{\circ} \mathrm{N}\right)$ was chosen for

85 formal analysis. Specifically, the data in use include vertical profiles of DO, temperature, salinity, dissolved inorganic nitrogen (DIN), and chlorophyll $a(\mathrm{Chl} a)$ concentrations measured in the water columns during 1994-2018 as well as total organic carbon (TOC) and total nitrogen (TN) measured in the sediments during 1998-2018. The survey stations can be divided into three subregions: (1) the northwestern subregion, including stations NM5 (with water depth of $20 \mathrm{~m}$ ), NM6 (5 $\mathrm{m}$ ), and NM8 (8 m); (2) the southern subregion, including stations SM20 (7 m), SM17 (12 m), SM18 (21 m), and SM19

90 (24m); and (3) the eastern subregion, including stations MM8 (31 m), MM13 (28 m), and MM14 (25 m). Water samples were collected from the surface ( $1 \mathrm{~m}$ below the sea surface), middle (half of the depth at each station), and bottom (1 $\mathrm{m}$ above the sediments) layers, respectively. Details on the sampling procedures and measurements were described in (Xu et al., 2010).

In addition, the monthly data of wind speeds and duration of southwesterly winds used for analysis were estimated 95 using the daily wind observations during 1994-2018 provided by the Waglan Island automatic weather station (Figure 1) of 
https://doi.org/10.5194/bg-2021-358

Preprint. Discussion started: 19 January 2022

(c) Author(s) 2022. CC BY 4.0 License.

(c) (i)

the Hong Kong Observatory. It should be noted that the duration of southwestern winds was defined as the number of its occurrence in days during summer. As for the freshwater inputs from the Pearl River, the monthly data during 1994-2018 were calculated using the discharge data obtained from three major hydrological stations (i.e. Gaoyao, Shijiao, and Boluo) of the Pearl River Water Resources Commission of the Ministry of Water Resources.

\subsection{Statistical methods}

Several metrics, including the cross-sectional area and the layer thickness of low oxygen (DO $<4 \mathrm{mg} / \mathrm{L}$ ), oxygen deficiency (DO $<3 \mathrm{mg} / \mathrm{L}$ ) and hypoxia ( $\mathrm{DO}<2 \mathrm{mg} / \mathrm{L}$ ) as well as the mean and minimum DO concentrations in the bottom waters, were used to depict the oxygen conditions in the region. Firstly, the observed DO profiles were interpolated by MATLAB along the three subregions with a grid resolution of $600 \mathrm{~m}$ (length) $\times 0.3 \mathrm{~m}$ (depth). The total areas of DO below

$1054 \mathrm{mg} / \mathrm{L}, 3 \mathrm{mg} / \mathrm{L}$, and $2 \mathrm{mg} / \mathrm{L}$ were then calculated as the cross-sectional areas of low oxygen, oxygen deficiency, and hypoxia, respectively. The associated layer thickness was defined as the averaged thickness of the grids with DO below the corresponding levels (i.e. $4 \mathrm{mg} / \mathrm{L}, 3 \mathrm{mg} / \mathrm{L}$, and $2 \mathrm{mg} / \mathrm{L}$ ).

In order to describe the severity of low-oxygen conditions comprehensively, we have also introduced an indicator integrating the above metrics (except the hypoxic area and thickness) through the PCA (principal component analysis) technique, which can reduce the dimensionality of a dataset to make it more interpretable with minimum information loss (Cadima et al., 2016). The two metrics related to hypoxia were excluded from PCA because the occurrence of hypoxia was relatively rare and its interannual variation was not as significant as that of low oxygen and oxygen deficiency. The first component of PCA analysis explained $86.40 \%$ variance of all the input variables and was thereafter referred to as the Lowoxygen Index (LOI, Equ. 1), which was highly correlated with the cross-sectional areas (with a correlation coefficient $r$ of

$1150.96, p<0.01)$ and the thickness $(r=0.96, p<0.01)$ of low oxygen as well as the bottom DO concentrations $(r=-0.90, p<$ $0.01)$.

LOI $=-0.40 \times \mathrm{DO}_{\text {mean }}-0.39 \times \mathrm{DO}_{\text {min }}+0.42 \times$ Area $_{4}+0.41 \times$ Area $_{3}+0.42 \times$ Thickness $_{4}+0.41 \times$ Thickness $_{3}$

where $\mathrm{DO}_{\text {mean }}$ and $\mathrm{DO}_{\text {min }}$ represent the mean and the minimum $\mathrm{DO}$ concentrations in the bottom waters, respectively; Area (Area $)_{3}$ and Thickness 4 (Thickness 3 ) represent the cross-sectional area and the thickness of low oxygen (oxygen deficiency), respectively.

To quantify the relative contribution of each primary process to interannual variability in the oxygen conditions, the monthly averaged wind speed (WS) and freshwater discharge (flow) as well as the monthly spatial-average of bottom temperature (T) and surface DIN in the summer (June-August) were adopted to fit the LOI defined above through the multiple regression analysis. The resulting regression coefficients were then standardized by multiplying the ratio between the standard deviation of each input variable (e.g. WS) and the standard deviation of LOI to evaluate their interannual contributions. In addition, the dataset was randomly split into a training dataset (70\%) and a testing dataset (30\%) in order to provide a more robust data fitting with estimates on the uncertainties arising from different data selections. Consequently, over 480,700 combinations of training and testing datasets were generated from this splitting process and were used to build 
https://doi.org/10.5194/bg-2021-358

Preprint. Discussion started: 19 January 2022

(c) Author(s) 2022. CC BY 4.0 License.

(c) (i)

up a variety of regression models. Of all the established models, only those with coefficients of determination $\left(\mathrm{R}^{2}\right)$ over 0.6 both for the training and testing datasets were selected to quantify the impact of each input variable according to their regression coefficients on average. Furthermore, based on the selected models (with $\mathrm{R}^{2}$ over 0.6 for both datasets), we also set up four sensitive experiments in which the long-term trend of each input variable was removed and only interannual fluctuations were retained. The LOI was then re-calculated in each scenario and its change relative to the original LOI was used to assess the impact of each variable to the long-term oxygen trend.

\section{3. Result}

\subsection{Seasonal and interannual variabilities in water quality variables in the eastern Pearl River Estuary}

\subsubsection{Hydrological and eutrophication parameters}

Significant seasonal variations could be found for the hydrologic settings (Figure 2). In winter (December-February), temperature generally exhibited low levels, with climatological mean values of $18.62{ }^{\circ} \mathrm{C}$ and $18.54{ }^{\circ} \mathrm{C}$ during $1994-2018$ in the surface (Figure 2a) and the bottom waters (Figure 2b), respectively; salinity reached high values due to the invasion of shelf saline waters, with means of 32.05 PSU at the surface (Figure 2c) and 32.44 PSU at the bottom (Figure 2d). Small differences of temperature and salinity between the surface and the bottom layers in winter indicated that the water column was well mixed (with mean vertical density differences of $0.33 \mathrm{~kg} / \mathrm{m}^{3}$; Figure 2e). By comparison, temperature and salinity in summer (June-August) showed larger vertical gradients and interannual variability. The summertime temperature varied by $28.21 \pm 1.19{ }^{\circ} \mathrm{C}$ (i.e. climatological mean \pm one standard deviation) at the surface, which was markedly higher than that at the bottom $\left(24.93 \pm 2.14^{\circ} \mathrm{C}\right)$. As affected by massive freshwater inputs from the Pearl River, salinity in summer was much lower than that in winter and displayed pronounced vertical differences with $22.86 \pm 7.53 \mathrm{PSU}$ at the surface and $30.90 \pm 5.26$ PSU at the bottom, respectively. Consequently, strong water stratification prevailed in summer, where the vertical density differences $(\Delta \rho)$ varied by $7.26 \pm 4.54 \mathrm{~kg} / \mathrm{m}^{3}$ (Figure $2 \mathrm{e}$ ).

DIN and Chl $a$ are two important parameters related to eutrophication and they both showed remarkable changes over time (Figure 3a-d). In winter, the concentrations of DIN and Chl $a$ were generally low, with climatological means of 0.19 $\mathrm{mg} / \mathrm{L}$ (surface) and $0.16 \mathrm{mg} / \mathrm{L}$ (bottom) for DIN and means of $2.45 \mu \mathrm{g} / \mathrm{L}$ (surface) and $2.04 \mu \mathrm{g} / \mathrm{L}$ (bottom) for Chl $a$. While in summer, DIN and Chl $a$ reached comparatively high levels with significant interannual variability. Overall, the DIN content varied by $0.56 \pm 0.50 \mathrm{mg} / \mathrm{L}$ at the surface (Figure 3a), which was higher that at the bottom $(0.28 \pm 0.34 \mathrm{mg} / \mathrm{L}$; Figure

$1553 \mathrm{~b}$ ). Chl $a$ also showed considerable vertical differences with $8.56 \pm 9.30 \mu \mathrm{g} / \mathrm{L}$ at the surface (Figure $3 \mathrm{c}$ ) and $2.46 \pm 4.13 \mu \mathrm{g} / \mathrm{L}$ at the bottom (Figure 3d).

In terms of spatial distributions, distinct differences were observed for the hydrological and eutrophication parameters among the three subregions investigated. Due to the profound influence of river discharges, temperature/salinity in the northwestern subregion (NM5-NM8, closer to the river outlets) was noticeably higher/lower when compared to the other two 
https://doi.org/10.5194/bg-2021-358

Preprint. Discussion started: 19 January 2022

(c) Author(s) 2022. CC BY 4.0 License.

(c) (i)

160 (Figure $2 \mathrm{a}-\mathrm{d}$ ), varying by $28.61 \pm 1.09{ }^{\circ} \mathrm{C} / 14.63 \pm 6.23 \mathrm{PSU}$ at the surface in summer. Meanwhile, the DIN concentration in the northwestern subregion was the highest (Figure $3 \mathrm{a}-\mathrm{b}$ ), reaching up to $1.17 \pm 0.40 \mathrm{mg} / \mathrm{L}$ at the surface. On the contrary, the eastern subregion (MM8-MM14), which was farthest to the river outlets and more heavily affected by the shelf water, had the lowest temperature $\left(27.85 \pm 1.27^{\circ} \mathrm{C}\right)$, highest salinity (29.22 $\left.\pm 3.10 \mathrm{PSU}\right)$ and lowest DIN concentration $(0.14 \pm 0.13 \mathrm{mg} / \mathrm{L})$ in the surface waters. As for Chl $a$ (Figure 3c-d), the highest level appeared in the southern subregion (SM17-SM20, with

$16510.19 \pm 8.86 \mu \mathrm{g} / \mathrm{L}$ at the surface in summer), while the lowest one was found at the northwestern subregion (with $6.82 \pm 10.67$ $\mu \mathrm{g} / \mathrm{L}$ at the surface).

\subsubsection{Dissolved oxygen and low-oxygen conditions}

With respect to DO, it exhibited significant seasonal and interannual variations in both layers (Figure 3e-f). The DO content maintained at higher levels during winter (with $7.07 \pm 0.99 \mathrm{mg} / \mathrm{L}$ and $7.27 \pm 0.87 \mathrm{mg} / \mathrm{L}$ in the surface and the bottom

170 waters over 1994-2018, respectively) and dropped to a level of $6.91 \pm 1.71 \mathrm{mg} / \mathrm{L}$ at the surface and $4.42 \pm 1.37 \mathrm{mg} / \mathrm{L}$ at the bottom in summer. Statistic results showed that low-oxygen events mainly appeared in the bottom waters of summer, which had much higher occurrences of DO $<4 \mathrm{mg} / \mathrm{L}$ and $\mathrm{DO}<2 \mathrm{mg} / \mathrm{L}$ compared to other seasons and other layers (with the occurrences mostly less than 10\%; Appendix figure A1). In addition, the summertime DO minimum at the bottom (Figure 4a) varied by $2.28 \pm 0.89 \mathrm{mg} / \mathrm{L}$, further indicating the water quality deterioration with severe oxygen deficits in the eastern PRE.

175 Among the three subregions, the northwestern and the southern ones had relatively lower bottom DO levels (with $4.56 \pm 1.56$ $\mathrm{mg} / \mathrm{L}$ and $4.14 \pm 1.45 \mathrm{mg} / \mathrm{L}$, respectively) and considerably higher occurrences of low-oxygen conditions (with $38.76 \%$ and $49.32 \%$, respectively) compared to the eastern subregion (with DO of $4.68 \pm 0.93 \mathrm{mg} / \mathrm{L}$ and occurrence of $17.24 \%$; Appendix figure A1).

In addition to the DO levels, we also investigated the interannual changes in the summertime low-oxygen conditions in terms of areal extents (vertical profiles), thickness, and the LOI as defined in section 2.2 (Figure 4). Significant interannual fluctuations were found for all these metrics; for example, the area and thickness affected by low oxygen varied by (3.35 \pm $2.38) \times 10^{5} \mathrm{~m}^{2}$ and $5.66 \pm 4.01 \mathrm{~m}$, respectively, while those for oxygen deficiency were $(7.13 \pm 8.37) \times 10^{4} \mathrm{~m}^{2}$ and $1.20 \pm$ $1.41 \mathrm{~m}$. Low-oxygen and hypoxic conditions were more severe in the years such as 2007, 2011, and 2017, as indicated by the high LOI values. In particular, the year 2011 had the largest low-oxygen area $\left(\sim 7.66 \times 10^{5} \mathrm{~m}^{2}\right)$ and the lowest DO concentration $(\sim 0.40 \mathrm{mg} / \mathrm{L})$ over the past 25 years, thus possessing the highest LOI; it could be observed that the low-oxygen waters almost occupied the entire middle-to-bottom layers across all the sites during this period (Appendix figure A2). On the other hand, hypoxic conditions were absent in some years (e.g. 2004, 2006, and 2018), where the water column resided in a comparatively well-oxygenated status (Appendix figure A2); the corresponding LOI in these hypoxia-relief years fell to large negative values (Figure 4d). 
https://doi.org/10.5194/bg-2021-358

Preprint. Discussion started: 19 January 2022

(c) Author(s) 2022. CC BY 4.0 License.

\subsection{Long-term trends of low-oxygen conditions in the eastern Pearl River Estuary}

Despite the large DO fluctuations by years, a clear deoxygenation trend could be observed in summer over the past 25 years, showing a long-term decline in the DO content associated with increases in the areas and occurrences affected by low oxygen (Figure 4). More specifically, before 2000 the spatially-averaged DO concentrations in the bottom waters exceeded 4 $\mathrm{mg} / \mathrm{L}$ and low-oxygen conditions were seldom observed (Figure $4 \mathrm{a}$ ), while the DO minimums were all above $2 \mathrm{mg} / \mathrm{L}$ (i.e. no hypoxic events occurred). However, since 2000 the occurrences of low oxygen and hypoxia have become more frequent, with a significant growth in the LOI and its related metrics, confirming the exacerbation of low-oxygen conditions in the eastern PRE.

To further quantify the intensity of long-term deoxygenation in summer, linear regressions were performed for the DO contents in different layers and in different subregions and also for the areal extents of low-oxygen conditions during 1994-

2018 (Figure 5). As shown, apparent declining trends were found for the DO series both at the surface (although not significant, Figure 5a) and the bottom (Figure $5 \mathrm{~b}$ ). For the bottom waters, the averaged DO concentrations displayed a decreasing pattern with a rate of $0.03 \mathrm{mg} / \mathrm{L}$ per year (equivalent to approximately $0.7 \%$ of the climatological DO mean at the bottom), while the DO minimums showed a more significant decline with a rate of $0.08 \mathrm{mg} / \mathrm{L}$ per year $(\sim 3.5 \%$ of the climatological mean of the bottom DO minimums). It was also noted that the intensity of deoxygenation varied between subregions (Figured 5c-h). As for the bottom DO content, the most significant decrease was found in the eastern subregion (with a deoxygenation rate of $0.05 \mathrm{mg} / \mathrm{L}$ per year, Figure $5 \mathrm{~h}$ ), while the most significant decline in the DO minimum appeared in the southern subregion (with a rate of $0.08 \mathrm{mg} / \mathrm{L}$ per year, Figure 5f). Likewise, significant increasing trends were also found for the areas of low oxygen and oxygen deficiency (Figure 5i-j), showing an annual growth rate at $1.95 \times 10^{4}$ $\mathrm{m}^{2}$ and $4.75 \times 10^{3} \mathrm{~m}^{2}$, respectively. Regarding the changes in LOI, it had a growth rate of 0.20 per year, which corresponds to an increasing rate of $1.99 \times 10^{4} \mathrm{~m}^{2}$ in the low-oxygen area and a declining rate of $0.07 \mathrm{mg} / \mathrm{L}$ in the DO minimum.

Furthermore, the long-term oxygen changes varied between different months of the summer season as well (Figure 6). It could be seen that the decreasing magnitude of the averaged DO concentration was close to each other for all the summer months, while the decline in the DO minimum was most pronounced in July (with a decreasing rate of $0.10 \mathrm{mg} / \mathrm{L}$ per year, Figure 6c), followed by that in August ( $0.06 \mathrm{mg} / \mathrm{L}$ per year, Figure 6e). In fact, the long-term changes in the DO minimum

215 had different patterns in July and August. As for July, the DO minimum generally showed a consecutive decrease over the past 25 years (Figure 6d). While in August, the DO minimum experienced a rapid decline with a rate of $0.14 \mathrm{mg} / \mathrm{L}$ per year during 1994-2011, which was higher than that in July during the same period $(0.11 \mathrm{mg} / \mathrm{L}$ per year), but subsequently undertook a recovery from the hypoxic conditions since 2012 (Figure 6f). Along with such distinctive intra-seasonal patterns, an interesting phenomenon was also noticed: hypoxic events were present mostly in August prior to 2012 (e.g. in 2007 and

220 2010-2011; no hypoxia was found in July during the same period) but only in July instead since 2012 (e.g. in 2014 and 2016 2017), as shown in Figure 6. This finding implied a potential shift in the onset of hypoxia generation from August to July, i.e. an earlier timing for the arrival of the summertime hypoxia. Accordingly, distinct changes were found for the areas affected 
https://doi.org/10.5194/bg-2021-358

Preprint. Discussion started: 19 January 2022

(c) Author(s) 2022. CC BY 4.0 License.

\section{(c) (i)}

by hypoxia in the two periods around 2012. The hypoxic area estimated in July increased from zero during 1994-2011 to $(5.42 \pm 8.77) \times 10^{3} \mathrm{~m}^{2}$ during 2012-2018, whereas the hypoxic area in August decreased from $(0.89 \pm 2.82) \times 10^{4} \mathrm{~m}^{2}$ to zero.

\section{Discussion}

\subsection{Primary factors controlling the interannual variabilities in low-oxygen conditions}

As shown above, significant interannual variabilities were observed in the spatial extent (e.g. cross-sectional area) and intensity of oxygen conditions (e.g. the mean bottom DO concentrations). Such variabilities were largely influenced by multiple physical and biogeochemical factors, including wind forcing, freshwater discharge, water temperature and nutrient loads. These processes jointly act to affect density stratification (Yu et al., 2015), water residence time (Li et al., 2021) and temporal and spatial distributions of eutrophication parameters (Cui et al., 2018). As described in section 2.2, four important influential factors (i.e. WS, flow, T, and DIN) were used to predict the interannual variations in LOI by the multiple regression models, in which there have been 56,010 cases $(\sim 12 \%$ of the total, Figure 7$)$ with $\mathrm{R}^{2}>0.6$ both in the training dataset (mean $\mathrm{R}^{2}$ of 0.64 ) and the testing dataset (mean $\mathrm{R}^{2}$ of 0.70 ). The standardized coefficients (mean \pm standard deviation)

for these well-performing regression cases were given as follows:

$\mathrm{LOI}=-(0.39 \pm 0.12) \times \mathrm{WS}-(0.14 \pm 0.12) \times$ flow $-(0.11 \pm 0.08) \times \mathrm{T}+(0.49 \pm 0.12) \times \mathrm{DIN}$

As denoted by the regression coefficients, wind forcing has exerted a significant impact on the interannual changes in LOI, with a relative contribution of $39 \% \pm 12 \%$ to the LOI variability explained. Its importance could also be evidenced by the significant negative correlation between WS and LOI $(r=-0.67, p<0.01$, Figure 8), suggesting that calm winds were beneficial to low-oxygen conditions. In most cases, strong winds could break down stratification in the water column (Rabalais et al., 1991; Feng et al., 2012b), which was conducive to water mixing and atmospheric reoxygenation (Rabalais et al., 1991). However, the weak correlation between WS and $\Delta \rho$ (Figure 8) indicated that the wind forcing may control hypoxia through other alternative mechanisms. Actually, weak winds in combination with flow convergence induced by wind-driven circulation could contribute to long water residence time and nutrient accumulation in the eastern PRE and thus favored the phytoplankton blooms ( $\mathrm{Li}$ et al., 2021). This could be supported by the significant negative correlation between WS and Chl $a(\mathrm{r}=-0.62, \mathrm{p}<0.01)$. With respect to the DIN content, it played a vital role in determining the interannual variabilities of the oxygen conditions, with a contribution up to $49 \% \pm 12 \%$. It has been widely recognized that eutrophication stimulated by anthropogenic nutrient inputs could provide a large quantity of depositing detritus and subsequently led to substantial oxygen depletion and occurrence of low-oxygen events (Rabalais et al., 2010; Fennel and Testa, 2018), as confirmed by the significant positive correlation between DIN and LOI $(r=0.65, p<0.01)$ in the present study. Collectively, DIN and WS were identified as the two key factors controlling the interannual changes in low-oxygen conditions.

Compared to WS and DIN, the freshwater discharges (flow) had a much smaller contribution $(\sim 14 \% \pm 12 \%)$ to the variations in LOI. Generally speaking, large freshwater inputs tend to enhance the intensity of water stratification and facilitate the generation of hypoxia (Rabalais et al., 1991). However, we found a negative correlation between flow and LOI 
https://doi.org/10.5194/bg-2021-358

Preprint. Discussion started: 19 January 2022

(c) Author(s) 2022. CC BY 4.0 License.

(c) (i)

$255(\mathrm{r}=-0.45, \mathrm{p}<0.05$, Figure 8$)$, implying that the effect of freshwater discharges on low-oxygen conditions might involve more complex mechanisms and act through indirect pathways; for example, the weakened discharge could prolong the residence time of nutrients and thereby stimulate local productions of organic matter ( $\mathrm{Li}$ et al., 2021), which ultimately promoted oxygen depletion. Similarly, the contribution of water temperature (T) to the LOI changes was not significant either, as revealed by its weak correlation with LOI as well. Overall, the role of temperature and freshwater discharges in regulating the interannual oxygen variability in the eastern PRE appeared to be secondary.

\subsection{Drivers of the long-term deoxygenation trend}

The data over the past 25 years showed that the eastern PRE has experienced a notable long-term oxygen decline, especially for the DO minimum in the bottom waters. Based on the observed deoxygenation rate, the bottom DO minimum was expected to decrease by approximately $15 \%-70 \%$ in $5-20$ years (reaching a level of $0.4-1.6 \mathrm{mg} / \mathrm{L}$ ) compared to the climatological mean of 1994-2018. The impacts of influential factors on the long-term deoxygenation trend were then evaluated using the regression models mentioned in section 4.1 and quantified by the relative changes of LOI in the sensitive experiments (see details in section 2.2) compared to the original one. It was noted that WS exhibited a decreasing trend of $0.03 \mathrm{~m} / \mathrm{s}$ per year $(\mathrm{p}<0.05$, Figure $9 \mathrm{a})$ over the past 25 years, while DIN showed an increase with a rate of $0.01 \mathrm{mg} / \mathrm{L}$ per year $(\mathrm{p}<0.01$, Figure $9 \mathrm{e})$. The growth in DIN and decline in WS have led to a $56 \% \pm 10 \%$ and $39 \% \pm 14 \%$ increase in LOI

270 (Table 4), respectively, indicating that DIN and WS were the main driving factors for the long-term deoxygenation. On the other hand, significant long-term trends were also found for the freshwater discharges (with a decreasing rate of $4.19 \times 10^{2}$ $\mathrm{m}^{3} / \mathrm{s}$ per year, Figure $9 \mathrm{~b}$ ) and water temperature (with an increasing rate of $0.06{ }^{\circ} \mathrm{C}$ per year, Figure $9 \mathrm{~d}$ ), but their impacts were relatively small, resulting in a $16 \% \pm 14 \%$ increase and $11 \% \pm 9 \%$ decrease in LOI, respectively.

Despite the different influences of the factors mentioned above, they were likely to impose synergetic impacts on the low-oxygen conditions by aggravating eutrophication as discussed earlier; it could be observed that the long-term growth in $\mathrm{Chl} a$ (with a rate of $0.15 \mu \mathrm{g} / \mathrm{L}$ per year, Figure $9 \mathrm{f}$ ) matched well with the increase in LOI. Specifically, the significant increase in phytoplankton biomass was primarily due to the combined effects of more stable water-column condition and longer residence time facilitated by the weaken wind forcing and river discharges, higher nutrient levels, and lower water turbidity (Figure $9 \mathrm{~g}$ ) in recent years. Consequently, the elevated organic matter through phytoplankton primary production

280 would lead to strong oxygen consumption, thereby contributing to an expansion of low-oxygen conditions in terms of areal extent and intensity.

Moreover, with massive algal fragments provided by primary production, the composition of organic matter in the eastern PRE has probably changed and would cause substantial changes in the timing of hypoxia generation. As noted in section 3.2, the onset of hypoxia was observed to shift from August to July around 2012. To explore this issue, we first used

285 the ratio of TOC to TN measured in the sediments to estimate the main source of organic matter, with values of 14-30 pointing to a terrestrial source and values of 4-10 indicating a marine source from in-situ production (Bordovskiy, 1965; Meyers and Ishiwatari, 1993). It is clear that the TOC:TN showed a significant decreasing trend and was mostly below 10 
https://doi.org/10.5194/bg-2021-358

Preprint. Discussion started: 19 January 2022

(c) Author(s) 2022. CC BY 4.0 License.

(c) (i)

since 2012 (Figure 9h). This implied a shift in the dominant source of organic matter from terrestrial inputs to local production (marine-sourced). As such, oxygen consumption became faster because the marine-sourced organic matter was fresher and more active (Raymond and Bauer, 2001) and therefore the time required to reach hypoxia would be shortened. Furthermore, changes in the physical conditions provided sufficient time for more thorough decomposition of organic matter in July, which left less organic matter for August and thus weakened the deoxygenation therein.

\section{Conclusion}

We have comprehensively investigated the spatiotemporal characteristics of DO and various related water quality variables in the eastern PRE and found that low-oxygen conditions occurred mostly in the bottom waters of summer, with significant interannual variability and an apparent deoxygenation trend over the past 25 years. As quantified by statistic methods, the increasing DIN levels and the decreasing wind speeds, both of which would eventually lead to the intensification of eutrophication, contributed most to the interannual variations and long-term trend in LOI. Therefore, more marine-sourced organic matter was produced by the elevated primary production, leading to an exacerbation in low-oxygen conditions with larger areal extents as well as a potential earlier onset of the summertime hypoxia. By comparison, the freshwater inputs and water temperature had relatively small impacts on the long-term changes in LOI. To sum up, this study has shown that oxygen conditions in the eastern PRE have been deteriorating under the interactions of altered physical forcing (e.g. winds) and aggravated eutrophication and it would develop into a severe hypoxic state within the next two decades. Lastly, given the significant intra-seasonal variability in low-oxygen conditions during summer, it is of great importance to conduct more cruise surveys to collect estuary-wide observations on a longer time scale in order to fully capture the generation and development of hypoxia and to confirm the change in the timing of its arrival.

Data availability. The marine water quality and the sediment data during 1994-2018 from the HKEPD are available at https://www.epd.gov.hk/epd/epic/english/epichome.html, while the daily wind observation data from Waglan Island automatic

310 weather station are available at https://www.hko.gov.hk/sc/cis/climat.htm. Daily discharge data of hydrological stations (i.e. Gaoyao, Shijiao, and Boluo) can be collected at http://www.zwswj.com/cms/webfile/waterInfo/index.html.

Author contributions. Under the conceptualization of JH, ZC completed the data analysis and graphic visualization. This work was supervised by JH and SL. ZC wrote the paper with contributions from all co-authors and all co-authors contributed to the 315 review and editing of manuscript, especially for JH and BW.

Competing interests. The authors declare that they have no conflict of interest. 
https://doi.org/10.5194/bg-2021-358

Preprint. Discussion started: 19 January 2022

(c) Author(s) 2022. CC BY 4.0 License.

Acknowledgements. We would like to express gratitude to the Environmental Protection Department of Hong Kong, the

Waglan Island automatic weather station of the Hong Kong Observatory and the Pearl River Water Resources Commission of the Ministry of Water Resources for sharing the monitoring data.

Financial support. This work was supported by the Joint Research Fund of the National Natural Science Foundation of China and Guangdong Province (U1901209).

\section{References}

Bordovskiy, O. K.: Sources of organic matter in marine basins, Marine Geology, 3, 5-31, https://doi.org/10.1016/00253227(65)90003-4, 1965.

Breitburg, D., Levin, L., Oschlies, A., Grégoire, M., Chavez, F., Conley, D., Garcon, V., Gilbert, D., Gutiérrez, D., Isensee, K., Jacinto, G., Limburg, K., Montes, I., Naqvi, S. W. A., Pitcher, G., Rabalais, N., Roman, M., Rose, K., Seibel, B., and

330 Zhang, J.: Declining oxygen in the global ocean and coastal waters, Science (New York, N.Y.), 359, 10.1126/science.aam7240, 2018.

Cadima, Jorge, Jolliffe, Ian, and T.: Principal component analysis: a review and recent developments, Philosophical Transactions of the Royal Society Mathematical Physical \& Engineering Sciences, 2016.

Chi, L., Song, X., Yuan, Y., Wang, W., Cao, X., Wu, Z., and Yu, Z.: Main factors dominating the development, formation

335 and dissipation of hypoxia off the Changjiang Estuary (CE) and its adjacent waters, China, Environmental Pollution, 265, 115066, https://doi.org/10.1016/j.envpol.2020.115066, 2020.

Conley, D., Carstensen, J., Aigars, J., Axe, P., Bonsdorff, E., Eremina, T., Haahti, B.-M., Humborg, C., Jonsson, P., Kotta, J., Lännegren, C., Larsson, U., Maximov, A., Medina, M., Lysiak-Pastuszak, E., Remeikaite-Nikienė, N., Walve, J., Wilhelms, S., and Zillén, L.: Hypoxia Is Increasing in the Coastal Zone of the Baltic Sea, Environmental science \& technology, 45,

340 6777-6783, 10.1021/es201212r, 2011.

Cui, Y., Wu, J. X., Ren, J., and Xu, J.: Physical dynamics structures and oxygen budget of summer hypoxia in the Pearl River Estuary: Dynamical structures and oxygen budget of hypoxia, Limnology and Oceanography, 64, 10.1002/lno.11025, 2018 .

Dai, M., Zhai, W., Cai, W.-J., Callahan, J., Huang, B., Shang, S., Huang, T., Li, X., Lu, Z., Chen, W., and Chen, Z.: Effects

345 of an estuarine plume-associated bloom on the carbonate system in the lower reaches of the Pearl River estuary and the coastal zone of the northern South China Sea, Continental Shelf Research, 28, 1416-1423, https://doi.org/10.1016/j.csr.2007.04.018, 2008.

Diaz, R. J. and Rosenberg, R.: Spreading dead zones and consequences for marine ecosystems, Science, 321, 926-929, 10.1126/science.1156401, 2008.

350 Feng, Y., DiMarco, S., and Jackson, G.: Relative role of wind forcing and riverine nutrient input on the extent of hypoxia in the northern Gulf of Mexico, Geophysical Research Letters, 39, $2012 \mathrm{a}$.

Feng, Y., DiMarco, S. F., and Jackson, G. A.: Relative role of wind forcing and riverine nutrient input on the extent of hypoxia in the northern Gulf of Mexico, Geophysical Research Letters, 39, https://doi.org/10.1029/2012GL051192, 2012b.

Feng, Y., Fennel, K., Jackson, G. A., DiMarco, S. F., and Hetland, R. D.: A model study of the response of hypoxia to 355 upwelling-favorable wind on the northern Gulf of Mexico shelf, Journal of Marine Systems, 131, 63-73, https://doi.org/10.1016/j.jmarsys.2013.11.009, 2014.

Fennel, K. and Testa, J.: Biogeochemical Controls on Coastal Hypoxia, Annual Review of Marine Science, 11, 10.1146/annurev-marine-010318-095138, 2018.

Forrest, D., Hetland, R., and Dimarco, S.: Multivariable statistical regression models of the areal extent of hypoxia over the

360 Texas-Louisiana Shelf, Environmental Research Letters, 6, 045002, 10.1088/1748-9326/6/4/045002, 2011.

Hu, J., Zhang, Z., Wang, B., and Huang, J.: Long-term spatiotemporal variations and expansion of low-oxygen conditions in the Pearl River estuary: A study synthesizing observations during 1976-2017, 10.5194/bg-2020-480, 2021. 
https://doi.org/10.5194/bg-2021-358

Preprint. Discussion started: 19 January 2022

(c) Author(s) 2022. CC BY 4.0 License.

Laurent, A. and Fennel, K.: Time-Evolving, Spatially Explicit Forecasts of the Northern Gulf of Mexico Hypoxic Zone, Environmental Science \& Technology, 53, 14449-14458, 10.1021/acs.est.9b05790, 2019.

365 Li, D., Gan, J., Hui, C., Yu, L., Liu, Z., Lu, Z., Kao, S.-j., and Dai, M.: Spatiotemporal Development and Dissipation of Hypoxia Induced by Variable Wind-Driven Shelf Circulation off the Pearl River Estuary: Observational and Modeling Studies, Journal of Geophysical Research: Oceans, 126, e2020JC016700, https://doi.org/10.1029/2020JC016700, 2021.

Li, G., Liu, J., Diao, Z., Jiang, X., Li, J., Ke, Z., Shen, P., Ren, L., Huang, L., and Tan, Y.: Subsurface low dissolved oxygen occurred at fresh- and saline-water intersection of the Pearl River estuary during the summer period, Marine Pollution

370 Bulletin, 126, 585-591, https://doi.org/10.1016/j.marpolbul.2017.09.061, 2018.

Li, M., Lee, Y. J., Testa, J. M., Li, Y., Ni, W., Kemp, W. M., and Di Toro, D. M.: What drives interannual variability of hypoxia in Chesapeake Bay: Climate forcing versus nutrient loading?, Geophysical Research Letters, 43, 2127-2134, https://doi.org/10.1002/2015GL067334, 2016.

375 summer: Long-term spatio-temporal patterns, trends, and regulating factors, Marine Pollution Bulletin, 151, 110814, https://doi.org/10.1016/j.marpolbul.2019.110814, 2020.

Lu, Z., Gan, J., Dai, M., Liu, H., and Zhao, X.: Joint effects of extrinsic biophysical fluxes and intrinsic hydrodynamics on the formation of hypoxia west off the Pearl River Estuary, Journal of Geophysical Research: Oceans, 123, 6241-6259, 2018.

Ludsin, S. A., Zhang, X., Brandt, S. B., Roman, M. R., Boicourt, W. C., Mason, D. M., and Costantini, M.: Hypoxia-

380 avoidance by planktivorous fish in Chesapeake Bay: Implications for food web interactions and fish recruitment, Journal of Experimental Marine Biology and Ecology, 381, S121-S131, https://doi.org/10.1016/j.jembe.2009.07.016, 2009.

Luo, L., Li, S., and Wang, D.: Hypoxia in the Pearl River Estuary, the South China Sea, in July 1999, Aquatic Ecosystem Health \& Management, 12, 418-428, 10.1080/14634980903352407, 2009.

Meier, H. E. M., Eilola, K., Almroth-Rosell, E., Schimanke, S., Kniebusch, M., Höglund, A., Pemberton, P., Liu, Y., Väli,

385 G., and Saraiva, S.: Disentangling the impact of nutrient load and climate changes on Baltic Sea hypoxia and eutrophication since 1850, Climate Dynamics, 53, 1145-1166, 10.1007/s00382-018-4296-y, 2019.

Meyers, P. A. and Ishiwatari, R.: Lacustrine organic geochemistry - an overview of indicators of organic matter sources and diagenesis in lake sediments, Organic Geochemistry, 20, 867-900, https://doi.org/10.1016/0146-6380(93)90100-P, 1993.

Murphy, R., Kemp, W., and Ball, W.: Long-Term Trends in Chesapeake Bay Seasonal Hypoxia, Stratification, and Nutrient

390 Loading, Estuaries and Coasts, 34, 1293-1309, 10.1007/s12237-011-9413-7, 2011.

Ni, W., Li, M., and Testa, J. M.: Discerning effects of warming, sea level rise and nutrient management on long-term hypoxia trends in Chesapeake Bay, Science of The Total Environment, 737, 139717, https://doi.org/10.1016/j.scitotenv.2020.139717, 2020.

Obenour, D., Scavia, D., Rabalais, N., Turner, R., and Michalak, A.: Retrospective Analysis of Midsummer Hypoxic Area

395 and Volume in the Northern Gulf of Mexico, 1985-2011, Environmental science \& technology, 47, 10.1021/es400983g, 2013.

Rabalais, N., Turner, R., and Boesch, D.: A brief summary of hypoxia on the northern Gulf of Mexico continental shelf: 1985-1988, Geological Society, London, Special Publications, 58, 35-47, 10.1144/GSL.SP.1991.058.01.03, 1991.

Rabalais, N. N., Díaz, R. J., Levin, L. A., Turner, R. E., Gilbert, D., and Zhang, J.: Dynamics and distribution of natural and 400 human-caused hypoxia, Biogeosciences, 7, 585-619, 10.5194/bg-7-585-2010, 2010.

Rabouille, C., Conley, D. J., Dai, M. H., Cai, W. J., Chen, C. T. A., Lansard, B., Green, R., Yin, K., Harrison, P. J., Dagg, M., and McKee, B.: Comparison of hypoxia among four river-dominated ocean margins: The Changjiang (Yangtze), Mississippi, Pearl, and Rhône rivers, Continental Shelf Research, 28, 1527-1537, https://doi.org/10.1016/j.csr.2008.01.020, 2008.

Raymond, P. and Bauer, J.: Use of 14C and 13C natural abundances for evaluating riverine, estuarine, and coastal DOC and

405 POC sources and cycling: A review and synthesis, Organic Geochemistry, 32, 469-485, 10.1016/S0146-6380(00)00190-X, 2001.

Shi, Z., Liu, K., Zhang, S., Xu, H., and Liu, H.: Spatial distributions of mesozooplankton biomass, community composition and grazing impact in association with hypoxia in the Pearl River Estuary, Estuarine, Coastal and Shelf Science, 225, 106237, https://doi.org/10.1016/j.ecss.2019.05.019, 2019.

410 Su, J., Dai, M., He, B., Lifang, W., Gan, J., Guo, X., Zhao, H., and yu, F.: Tracing the origin of the oxygen-consuming organic matter in the hypoxic zone in a large eutrophic estuary: The lower reach of the Pearl River Estuary, China, Biogeosciences, 14, 4085-4099, 10.5194/bg-14-4085-2017, 2017. 
https://doi.org/10.5194/bg-2021-358

Preprint. Discussion started: 19 January 2022

(c) Author(s) 2022. CC BY 4.0 License.

(c) (i)

Testa, J., Murphy, R., Brady, D., and Kemp, W.: Nutrient- and Climate-Induced Shifts in the Phenology of Linked Biogeochemical Cycles in a Temperate Estuary, Frontiers in Marine Science, 5, 114, 10.3389/fmars.2018.00114, 2018.

415 Wang, B., Hu, J., Li, S., and Liu, D.: A numerical analysis of biogeochemical controls with physical modulation on hypoxia during summer in the Pearl River Estuary, 1-31 pp., 10.5194/bg-2016-454, 2016.

Wang, K., Cai, W.-J., Chen, J., Kirchman, D., Wang, B., Fan, W., and Huang, D.: Climate and Human-Driven Variability of Summer Hypoxia on a Large River-Dominated Shelf as Revealed by a Hypoxia Index, Frontiers in Marine Science, 8, 10.3389/fmars.2021.634184, 2021.

420 Wen, G., Liang, Z., Xu, X., Cao, R., Wan, Q., Ji, G., Lin, W., Wang, J., Yang, J., and Huang, T.: Inactivation of fungal spores in water using ozone: Kinetics, influencing factors and mechanisms, Water Research, 185, 116218, 10.1016/j.watres.2020.116218, 2020.

Xu, J., Yin, K. D., Liu, H., Lee, J., Anderson, D., Ho, A., and Harrison, P.: A comparison of eutrophication impacts in two harbours in Hong Kong with different hydrodynamics, Journal of Marine Systems, 83, 10.1016/j.jmarsys.2010.04.002, 2010.

425 Yin, K., Lin, Z., and Ke, Z.: Temporal and spatial distribution of dissolved oxygen in the Pearl River Estuary and adjacent coastal waters, Continental Shelf Research, 24, 1935-1948, https://doi.org/10.1016/j.csr.2004.06.017, 2004.

Yu, L., Fennel, K., and Laurent, A.: A modeling study of physical controls on hypoxia generation in the northern Gulf of Mexico, Journal of Geophysical Research: Oceans, 120, 5019-5039, https://doi.org/10.1002/2014JC010634, 2015.

Zhang, H. and Li, S.: Effects of Physical and Biochemical Processes on the Dissolved Oxygen Budget for the Pearl River

430 Estuary during Summer, Journal of Marine Systems, 79, 65-88, 10.1016/j.jmarsys.2009.07.002, 2010.

Zhang, W., Moriarty, J. M., Wu, H., and Feng, Y.: Response of bottom hypoxia off the Changjiang River Estuary to multiple factors: A numerical study, Ocean Modelling, 159, 101751, https://doi.org/10.1016/j.ocemod.2021.101751, 2021.

Zhou, Y., Scavia, D., and Michalak, A.: Nutrient loading and meteorological conditions explain interannual variability of hypoxia in Chesapeake Bay, Limnology and oceanography, 59, 373-384, 10.4319/1o.2014.59.2.0373, 2014.

435 Zhu, Z.-Y., Zhang, J., Wu, Y., Zhang, Y.-Y., Lin, J., and Liu, S.-M.: Hypoxia off the Changjiang (Yangtze River) Estuary: Oxygen depletion and organic matter decomposition, Marine Chemistry, 125, 108-116, https://doi.org/10.1016/j.marchem.2011.03.005, 2011. 
https://doi.org/10.5194/bg-2021-358

Preprint. Discussion started: 19 January 2022

(C) Author(s) 2022. CC BY 4.0 License.

(c) (1)

440 Table 1 Long-term trends in the fitted LOI on average for the selected regression cases with $\mathbf{R}^{2}>0.6$ (baseline) and for the sensitive experiments with respect to the effects of wind speeds (b), freshwater discharges (c), water temperature (d), and surface DIN concentrations (e).

\begin{tabular}{lll}
\hline Cases & Mean trend of LOI $\left(\mathrm{yr}^{-1}\right)$ & $\begin{array}{l}\text { Changes relative to } \\
\text { baseline (mean } \pm \text { std) }\end{array}$ \\
\hline (a) baseline & 0.15 & \\
(b) WS- detrended & 0.10 & $-(39 \% \pm 14 \%)$ \\
(c) flow-detrended & 0.13 & $-(16 \% \pm 14 \%)$ \\
(d) T-detrended & 0.17 & $+(11 \% \pm 9 \%)$ \\
(e) DIN-detrended & 0.07 & $-(56 \% \pm 10 \%)$ \\
\hline
\end{tabular}


https://doi.org/10.5194/bg-2021-358

Preprint. Discussion started: 19 January 2022

(c) Author(s) 2022. CC BY 4.0 License.

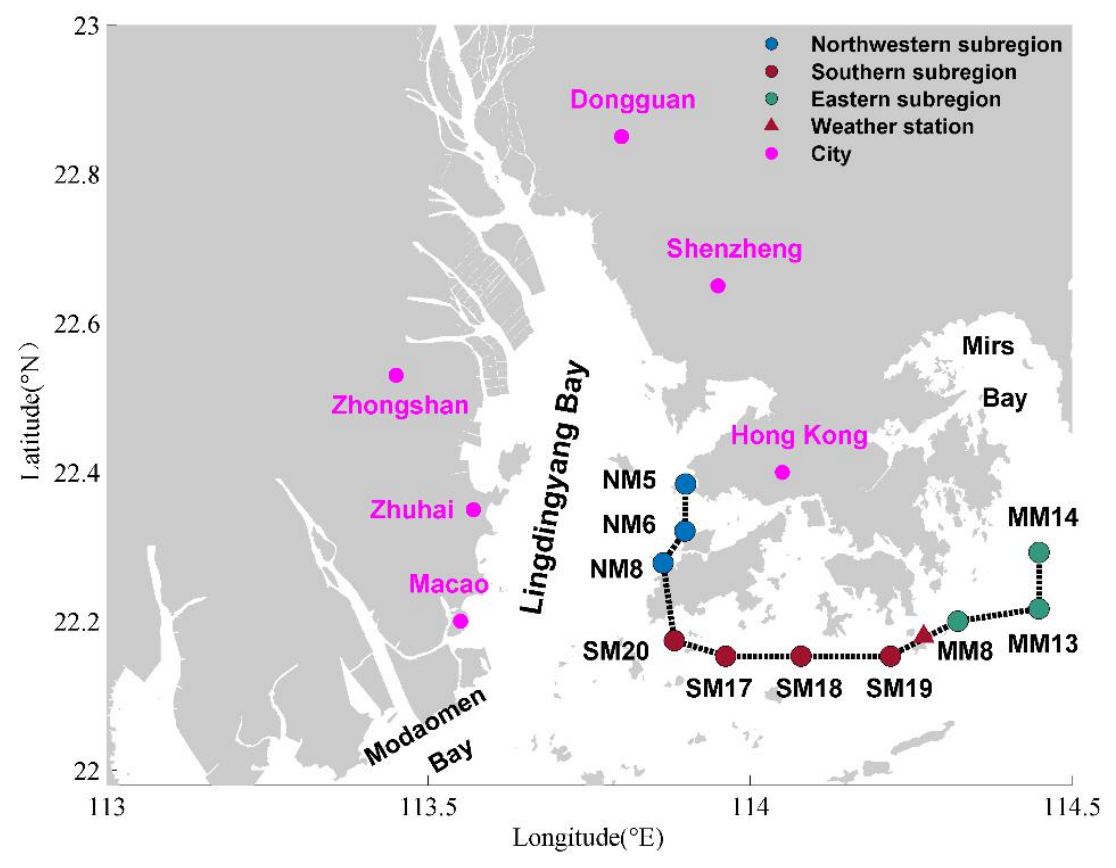

Figure 1. Map of the Pearl River Estuary (PRE) and monitoring stations in coastal waters of Hong Kong. Note that the blue, red, green dots represent stations in the northwestern, southern, eastern subregions of Hong Kong, respectively. The red triangle denotes the location of Waglan Island automatic weather station and the purple dots indicate the location of cities in the Guangdong-Hong Kong-Macao Greater Bay Area. 
https://doi.org/10.5194/bg-2021-358

Preprint. Discussion started: 19 January 2022

(c) Author(s) 2022. CC BY 4.0 License.
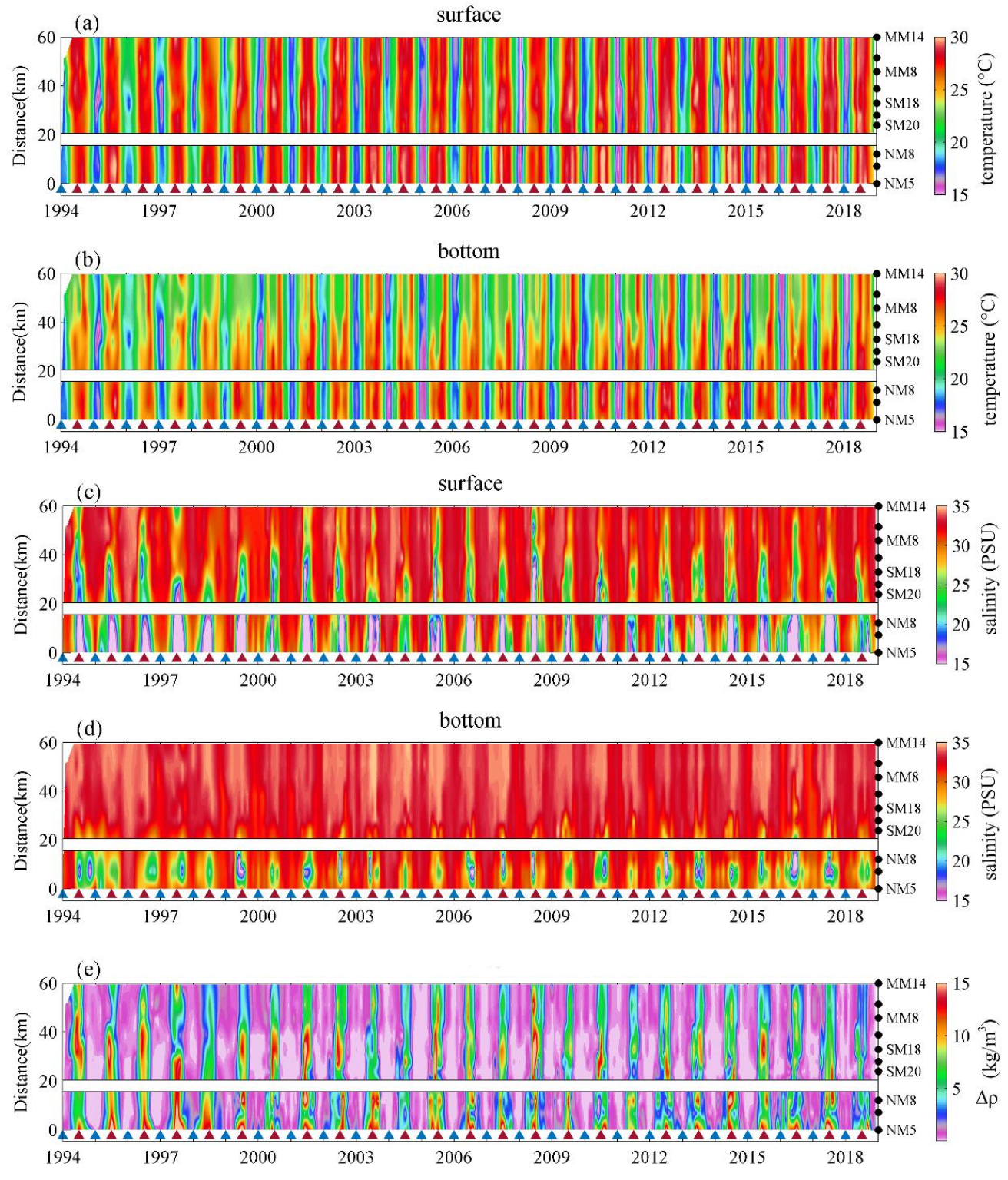

Figure 2. Spatiotemporal distribution of temperature (a-b), salinity (c-d) in the surface and bottom waters, and vertical density

differences (e) during 1994-2018. Note that the stations investigated are denoted by the black dots on the right of the figure. The blue triangles point at each December over 25 years, while the red ones point at July. 
https://doi.org/10.5194/bg-2021-358

Preprint. Discussion started: 19 January 2022

(c) Author(s) 2022. CC BY 4.0 License.
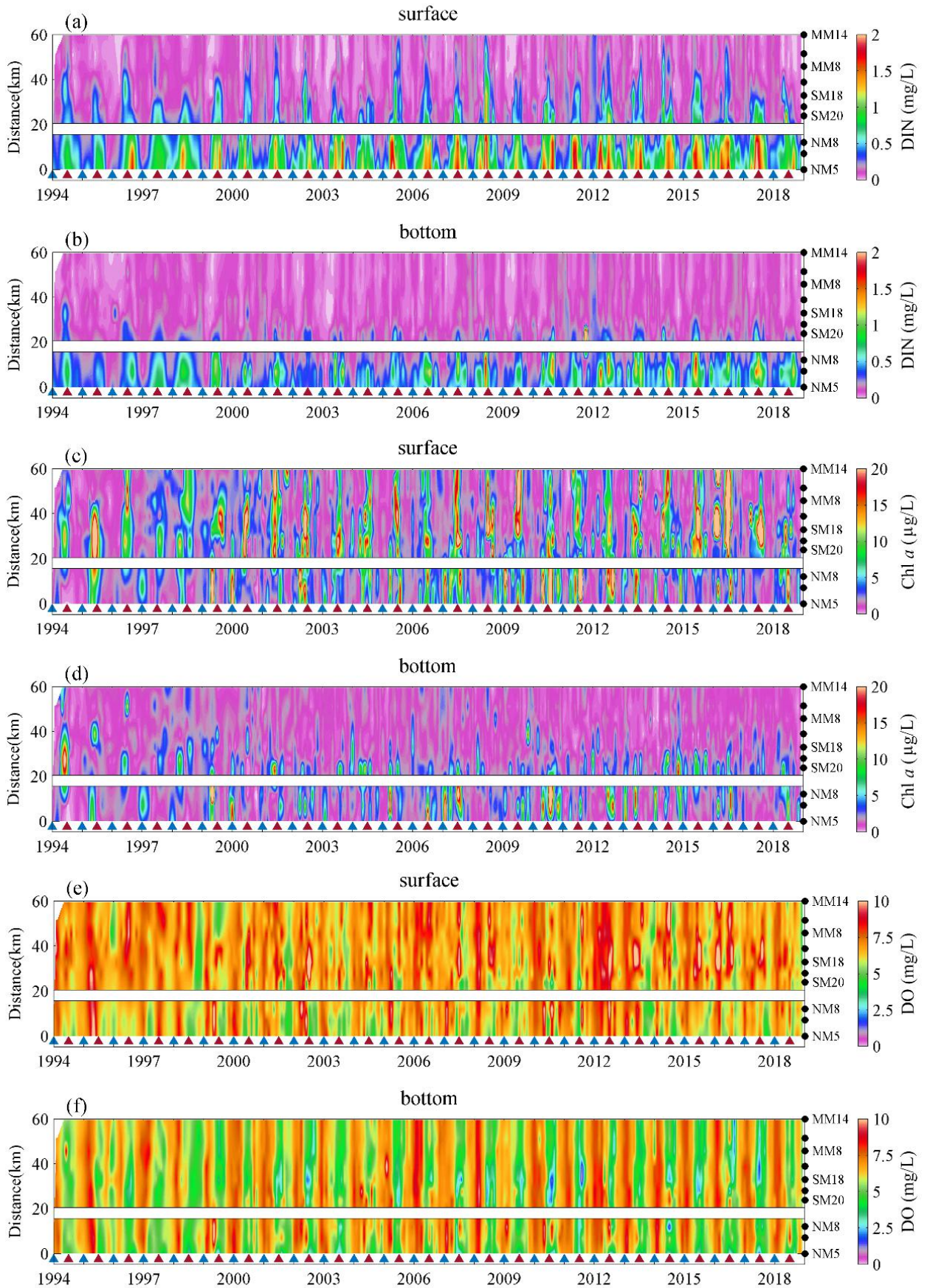

Figure 3. Same as Figure 2 but for concentrations of DIN (a-b), Chl $a$ (c-d) and DO (e-f). 
https://doi.org/10.5194/bg-2021-358

Preprint. Discussion started: 19 January 2022

(c) Author(s) 2022. CC BY 4.0 License.
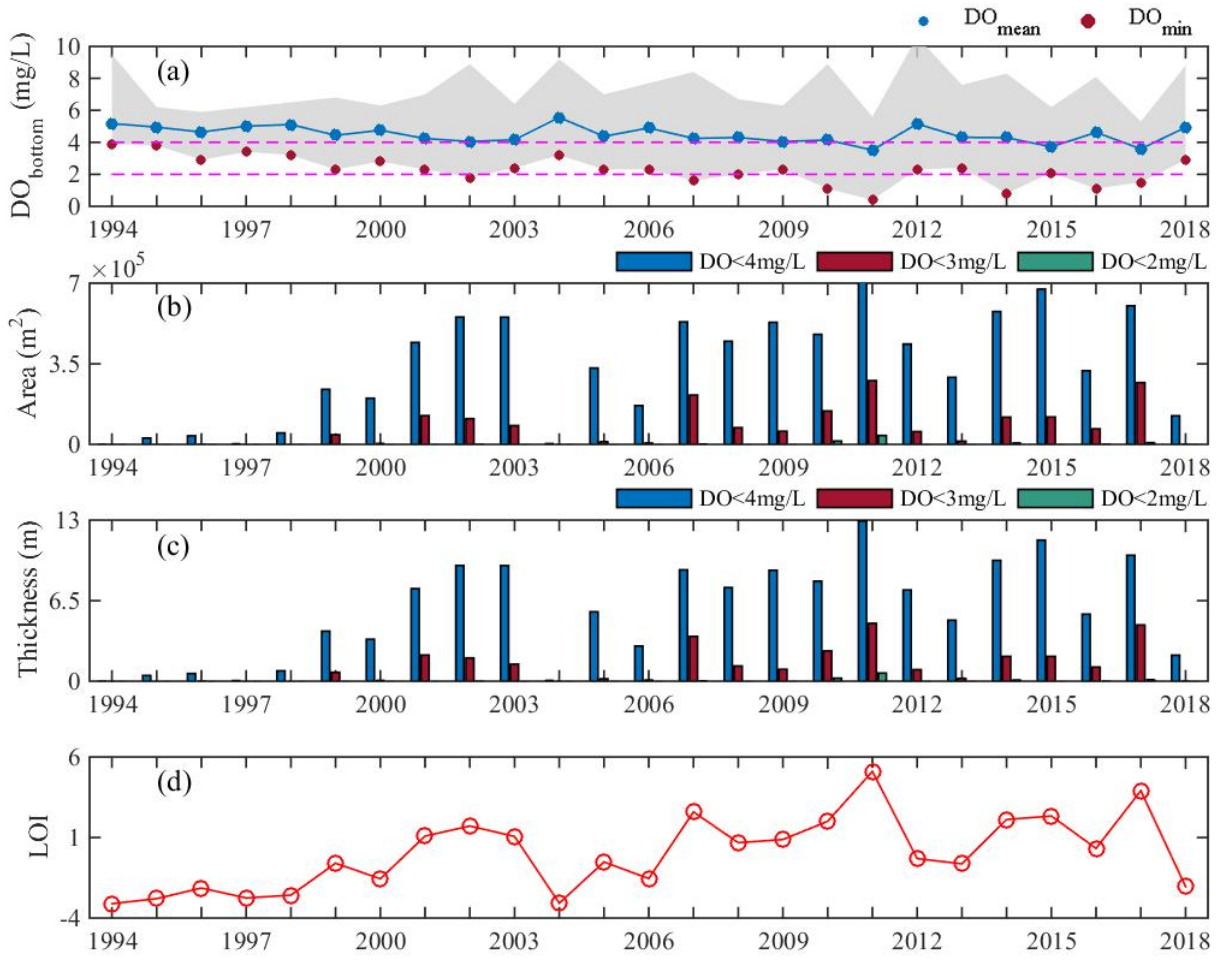

460 Figure 4. Interannual variations in the mean and minimum concentrations of DO at the bottom (a), the cross-sectional areas (b) and layer thicknesses (c) of low-oxygen conditions, and LOI (e) in summer during 1994-2018. 
https://doi.org/10.5194/bg-2021-358

Preprint. Discussion started: 19 January 2022

(c) Author(s) 2022. CC BY 4.0 License.
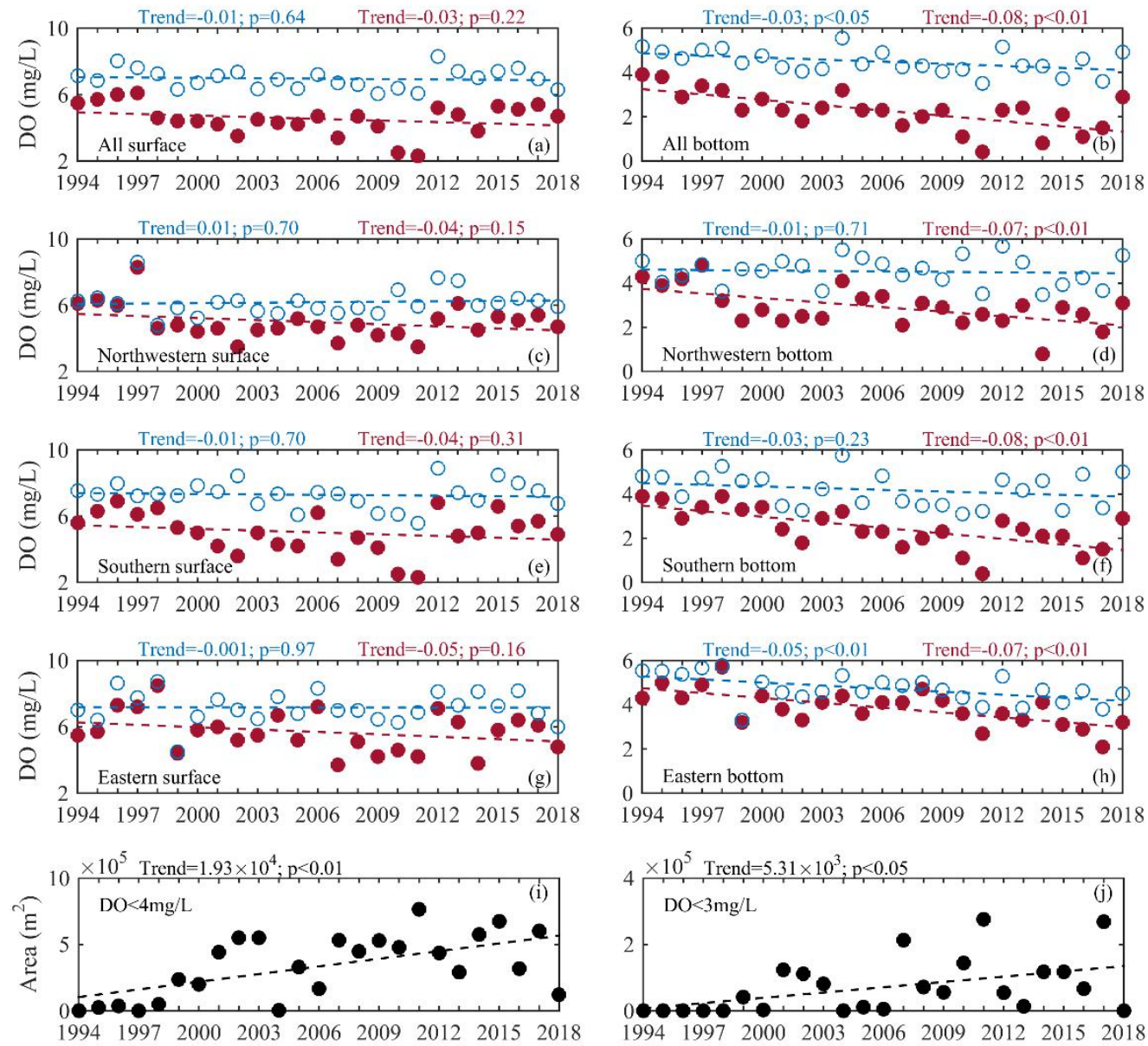

Figure 5. Long-term trends of the mean and minimum values of DO in the surface and bottom waters for all the stations (a-b) and for the northwestern (c-d), southern (e-f), and eastern (g-h) subregions, and long-term trends of the cross-sectional areas of low oxygen (i) and oxygen deficiency (j). 
https://doi.org/10.5194/bg-2021-358

Preprint. Discussion started: 19 January 2022

(c) Author(s) 2022. CC BY 4.0 License.
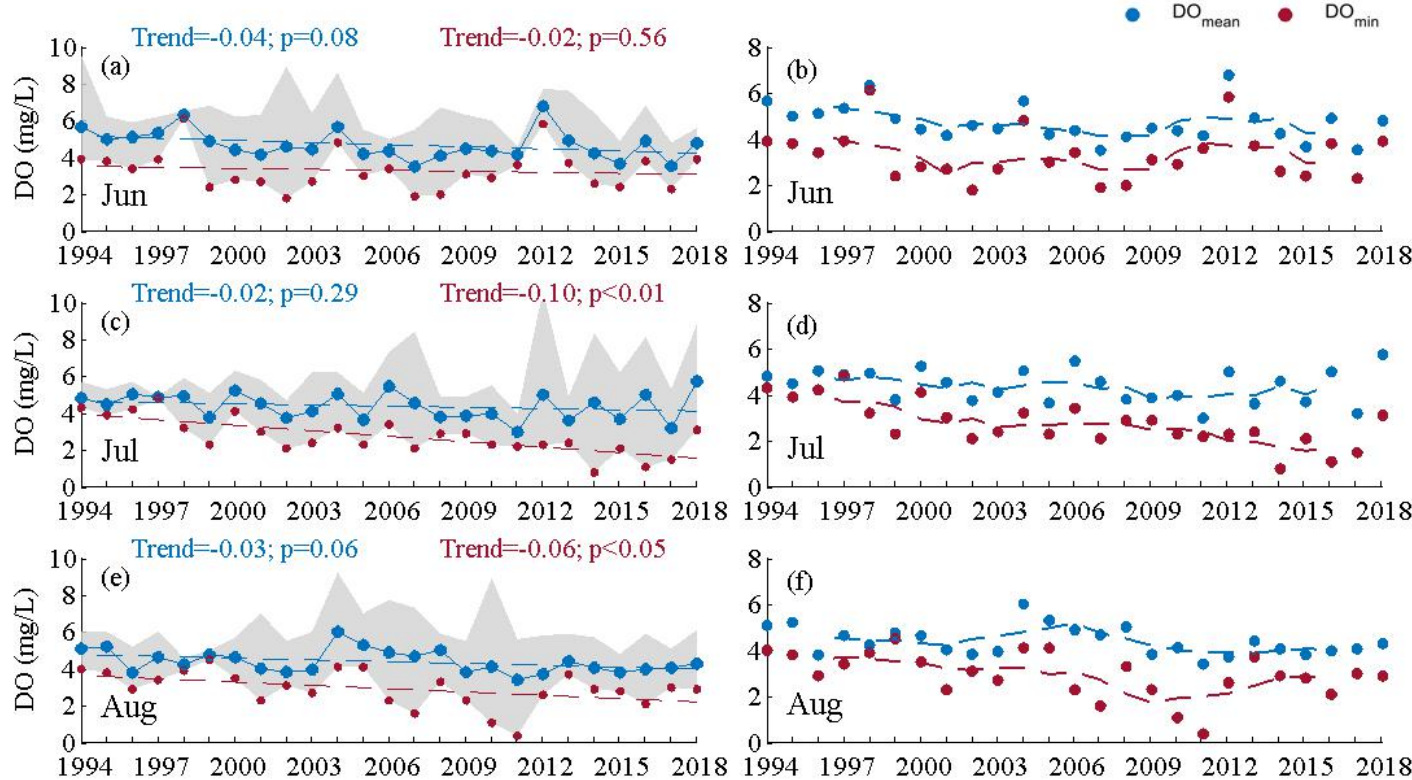

Figure 6. Mean and minimum concentrations of DO at the bottom with their long-term trends (a, c, e) and with five-year sliding mean values $(b, d, f)$ in summer months during 1994-2018. Note that the grey patches represent the range of DO observed in the 10 stations. 
https://doi.org/10.5194/bg-2021-358

Preprint. Discussion started: 19 January 2022

(c) Author(s) 2022. CC BY 4.0 License.

(c) (i)

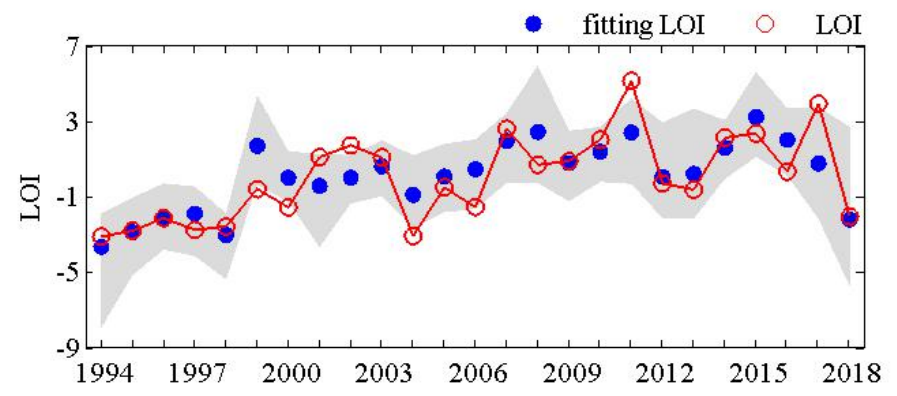

Figure 7. Combined fitting results of the regression models with $R^{2}>0.6$ both in the training dataset and the testing dataset. Note that the red hollow dots denote the LOI estimated based on observational data, while the blue solid dots and the gray patch represent the mean values and ranges of the fitted LOI in the selected regression cases, respectively. 
https://doi.org/10.5194/bg-2021-358

Preprint. Discussion started: 19 January 2022

(c) Author(s) 2022. CC BY 4.0 License.

(c) (i)

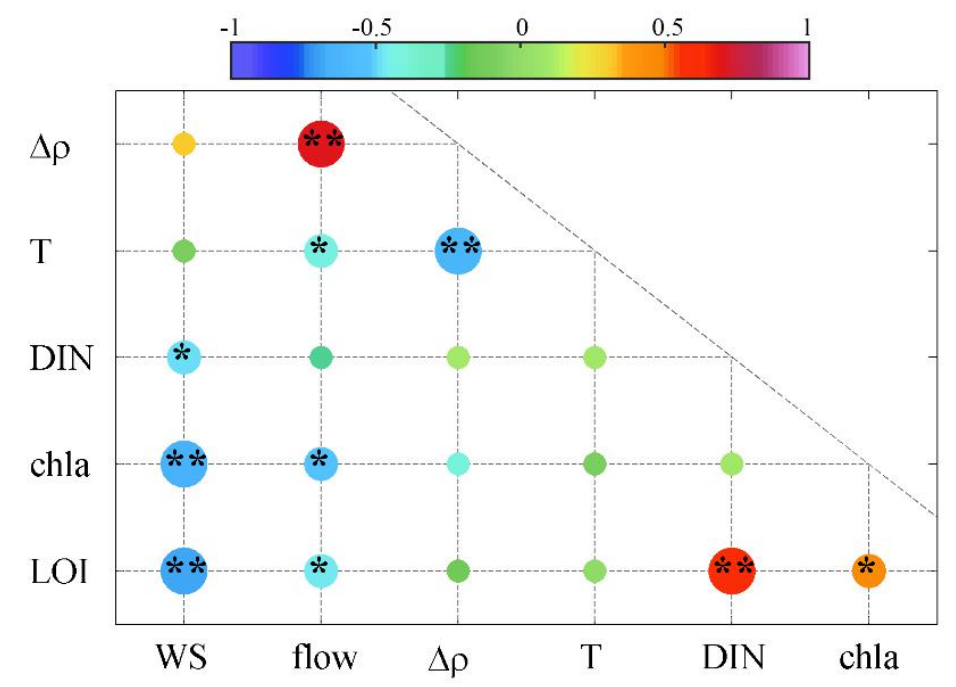

Figure 8. Pearson correlation coefficients (r) among the wind speeds (WS), freshwater discharges (flow), vertical density differences $(\Delta \rho)$, bottom temperature (T), surface DIN concentrations (DIN), surface Chl $a$ contents (Chl $a)$, and LOI. Note that the color of dots show the correlation coefficients, and the symbols $*$ and $* *$ represents the significant level at $p<0.05$ and $p<0.01$, respectively. 
https://doi.org/10.5194/bg-2021-358

Preprint. Discussion started: 19 January 2022

(c) Author(s) 2022. CC BY 4.0 License.
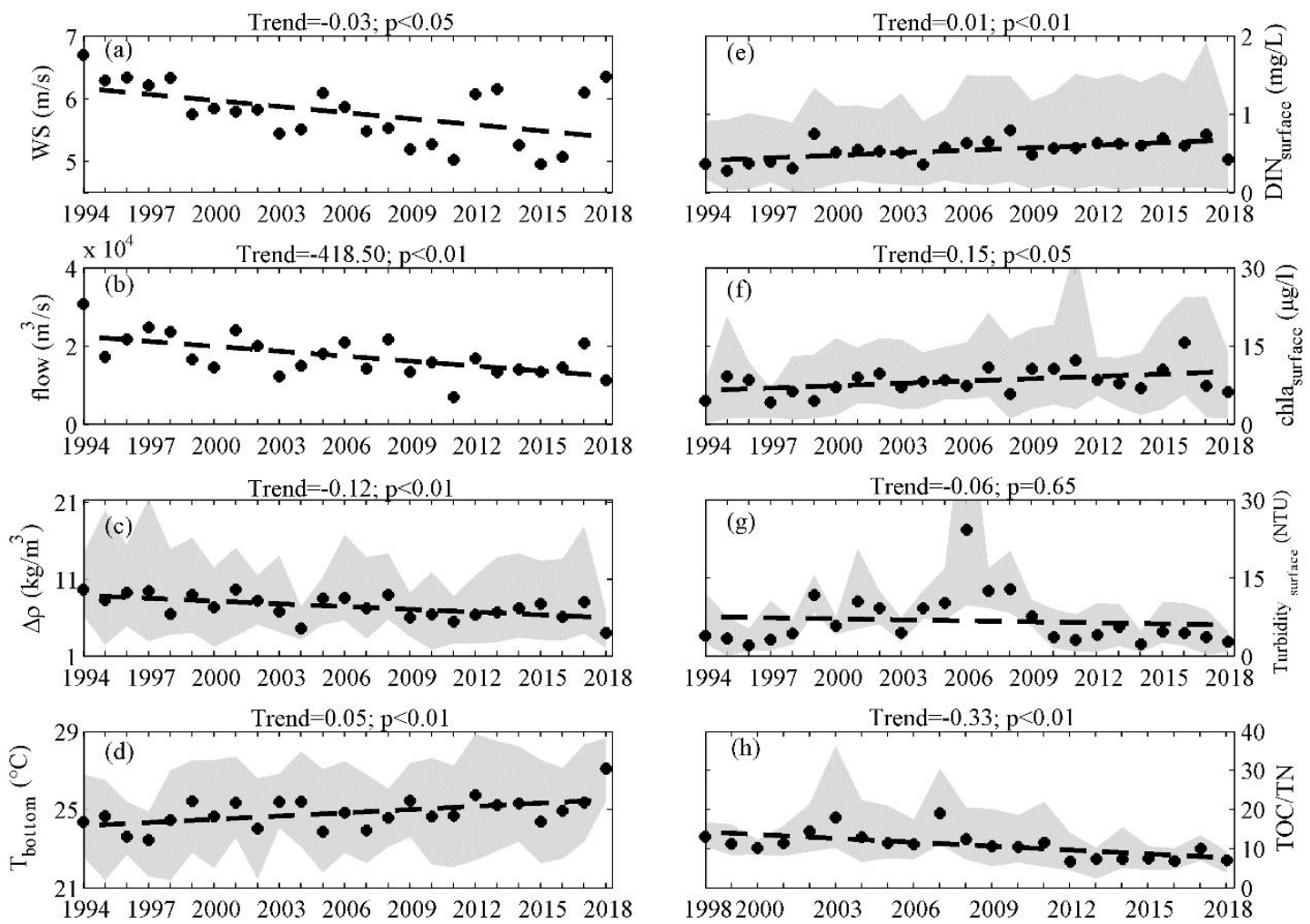

485 Figure 9. Long-term trends of the wind speeds (a), freshwater discharges (b), density differences (c), bottom temperature (d), surface DIN (e), surface Chl $a$ (f), surface turbidity (g), and TOC/TN measured in the sediments (h) in summer during $1998-2018$. Note that the black dots represent the spatial-average values of each variable and the grey patches represent the range of each variable observed in the 10 stations. 
https://doi.org/10.5194/bg-2021-358

Preprint. Discussion started: 19 January 2022

(c) Author(s) 2022. CC BY 4.0 License.

(c) (i)
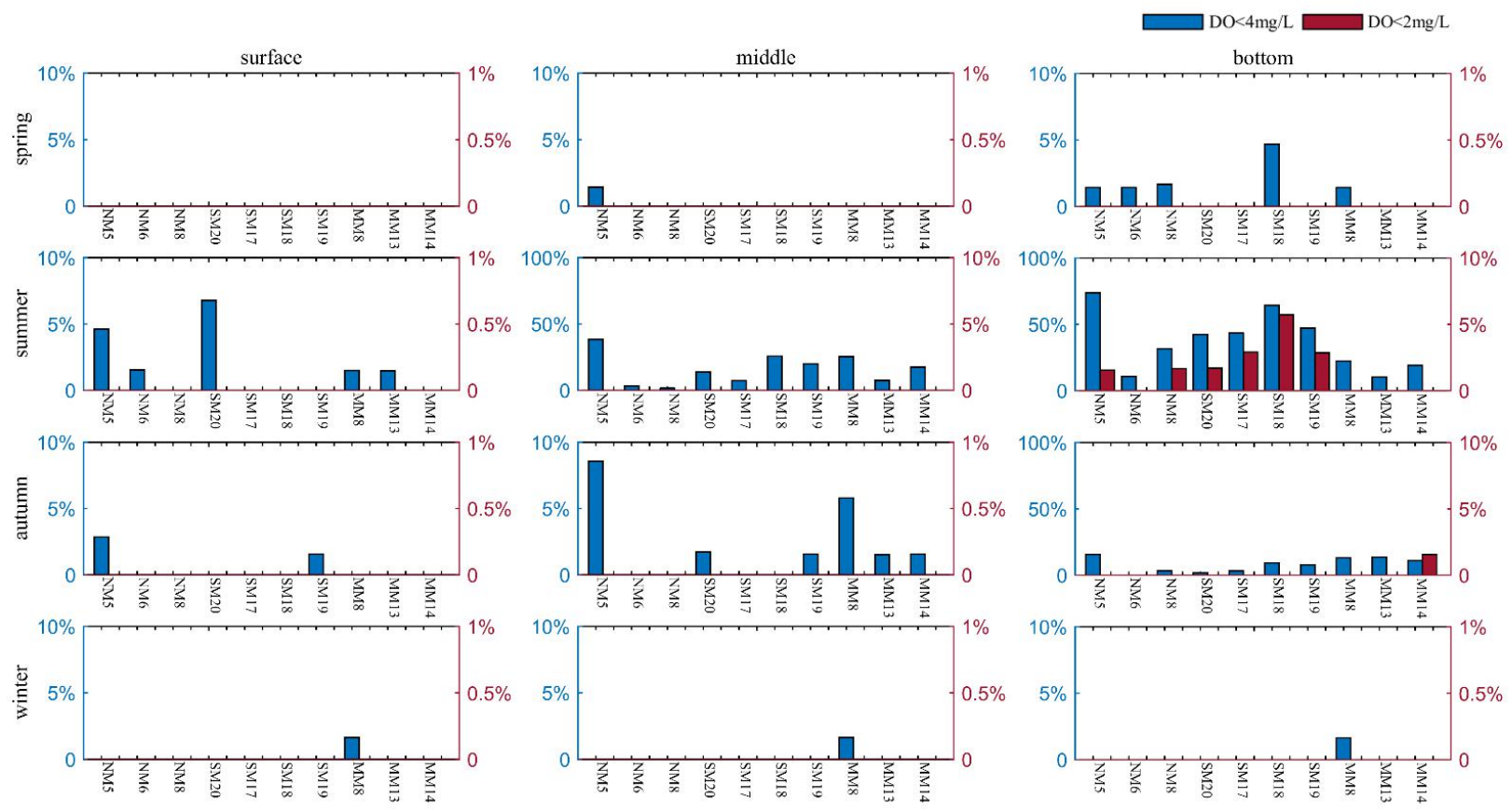

Figure A1. Frequencies of occurrence of low-oxygen and hypoxic events in four seasons at the surface, middle, and bottom layer. 
https://doi.org/10.5194/bg-2021-358

Preprint. Discussion started: 19 January 2022

(c) Author(s) 2022. CC BY 4.0 License.
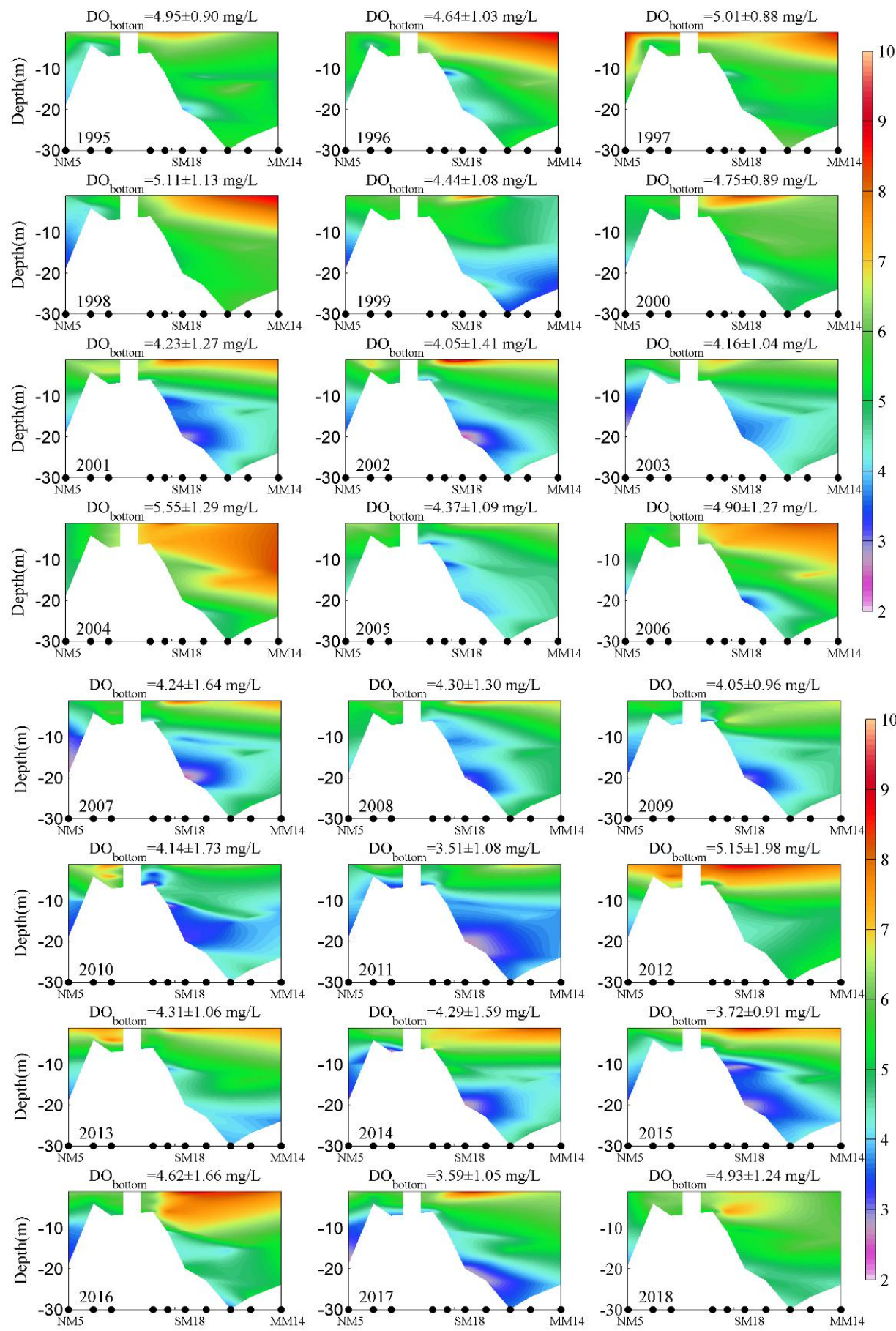

495 Figure A2. Vertical distributions of DO along the subregions in summer. Note that the mean values and standard deviations of bottom-water DO were also shown at the top of each subplot. 